\title{
A Review of Microstructural Evolution in the Adiabatic Shear Bands Induced by High Speed Machining
}

\section{Chunzheng DUAN ${ }^{\dagger}$ and Minjie WANG}

Key Laboratory for Precision and Non-Conventional Machining of the Ministry of Education, School of Mechanical Engineering, Dalian University of Technology, Dalian 116024, China

[Manuscript received 10 January 2013]

(C) The Chinese Society for Metals and Springer-Verlag Berlin Heidelberg

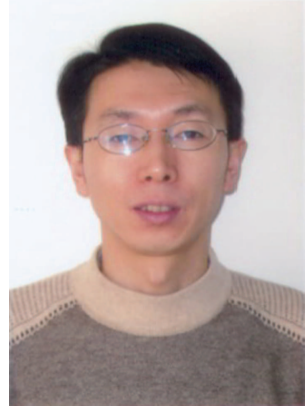

Chunzheng Duan, Associate Professor of Mechanical Engineering, Dalian University of Technology, China. He received his Ph.D. at Dalian University of Technology, and carried out research as a research fellow in School of Mechanical and Manufacturing Engineering of University of New South Wales, Australia in 2010-2011. His research areas include cutting theory and technology, high speed machining, advanced manufacture technology, microscopic behavior of materials under high speed loading. He has made contributions to adiabatic shear phenomenon during metal cutting. He published about 50 research papers, 6 papers got Academic Effort Award of Natural Science in Liaoning Province and Dalian City of China. He is a reviewer of several international journal including International Journal of Plasticity, International Journal of Impact Engineering, Machining Science and Technology and Journal of Materials Processing Technology. He was elected as excellent person of Fifth Talent Engineering in Liaoning Province of China in 2009 because of high quality research. His researches have been supported by National Natural Science Foundation of China.

\begin{abstract}
Investigations made by the authors and collaborators into the microstructural and fracture aspects of adiabatic shear bands (ASBs) of the hardened steels and Ti alloys induced by high speed machining (HSM) are briefly reviewed. The principal findings are the following: (a) the microstructure inside the ASBs varies from the band center to the normal chip material, the gradient microstructures are found; (b) the HSM can produce two types of ASBs with increasing in cutting speed, the deformed shear bands formed at lower cutting speed and the transformed shear bands formed at higher cutting speed; (c) the very small equiaxed recrystallized grains are observed in the center of the ASBs, the dynamic recrystallization and phase transformation may occur simultaneously during the formation of the transformed ASBs; (d) The dynamic rotational recrystallization is the origin of the equiaxed grains in the center of the ASBs. A microstructural evolution model in ASBs produced during HSM for the harden steel is proposed; (e) the microstructural pattern of fracture surface is characterised by the elongated dimples. A microcosmic adiabatic shear fracture model during HSM of the hardened steel is built up.
\end{abstract}

KEY WORDS: Adiabatic shear bands (ASBs); High speed machining (HSM); Microstructure; Fracture

\section{Introduction}

Adiabatic shear is the result of thermal-mecha-

† Corresponding author. Assoc. Prof.; Tel: $\quad+86411$ 84706062-801; E-mail address: duancz@dlut.edu.cn (Chunzheng DUAN)

DOI: $10.1007 / \mathrm{s} 40195-013-2001-\mathrm{z}$ nical instability in a material, which is localized in an extremely narrow adiabatic shear band (ASB) when thermal-softening exceeds strain hardening. Because of its technological importance it poses an interesting topic to researchers. In the past thirty years, the formation and microstructural evolution of ASB have received much attention from materials scientists. A large amount of researches 
on the ASBs have been reported in various kinds of the materials subjected to the high-strain-rate conditions such as ballistic impact ${ }^{[1-5]}$, explosive fragmentation ${ }^{[6-10]}$, dynamic compression ${ }^{[11-17]}$ and torsion $^{[18]}$, rolling ${ }^{[19,20]}$ and welding ${ }^{[21]}$. These materials include steels $^{[3,5,7,10,13,14,20]}$, aluminum alloys $^{[4,6]}$ magnesium alloys ${ }^{[1,20,21]}$, tantalum alloys $^{[16]}$, copper ${ }^{[17]}$, titanium alloys ${ }^{[2,8,9,11,12]}$ and Ni-based alloys ${ }^{[18]}$. Two types of ASBs, the "deformed shear bands" and the "transformed shear bands" [22-24], have been reported based on optical microscopy studies. For the former, it is caused by large plastic deformation, and the latter, the transformed shear bands which are also called the "whiteetching bands" sometimes, are associated with microstructural changes. Recent studies show that the formation of the microstructures in the ASBs depends on the materials and deformation processes ${ }^{[22]}$. The investigations have also reported that ASBs can have a broad range of microstructural alterations, such as recrystallization, phase transformation and $\operatorname{amorphization}^{[24]}$.

In recent twenty years, high speed machining (HSM) has become an important development area in advanced manufacturing technology. There are obvious differences in the material removal mechanisms between HSM and conventional machining. Serrated chip have frequently formed during HSM of the hardened steel, Ti alloys and Ni-Fe supper alloys ${ }^{[25-30]}$, which has a significant influence on cutting forces, cutting temperature, tool wear, and quality of machined surface $^{[31-34]}$, so the scientists have concerned the formation mechanism of serrated chip. The serrated chip formation during HSM is a typical material deformation process with large strain, high strain rate and heat concentration, the ASBs have been observed in the primary shear zones of serrated chips of some difficult-to-machining materials ${ }^{[35-44]}$. Adiabatic shear phenomenon has a decisive effect on the formation mechanism of the serrated chip, the investigations under different cutting conditions for the materials showed that the adiabatic shear instability and fracture in primary shear zone is a main reason for serrated chip formation under steady state cutting condition $^{[35-44]}$, therefore, the investigations of microstructure and fracture of ASBs will be helpful for revealing serrated chip formation mechanism.

There has been little work on the researches on sub-microstructure of ASBs produced in HSM during the past decade because of the difficulties of the specimen preparation for metallurgical examination, especially for transmission electron microscopy (TEM) specimens. In recent years, some research efforts have been reported since the problems of chip specimen preparation have been solved well ${ }^{[45-62]}$. This paper gives a review on the investigations of the ASBs formed during HSM for the hardened steels and Ti alloys over the past few years, including microhardness, microstructural characteristics, phase transformation, microstructural evolution, recrystallization and mi- croscopic fracture mechanism.

\section{Experimental Materials and Techniques}

$30 \mathrm{CrNi} 3 \mathrm{MoV}$ structural steel, AISI 1045 carbon steel and Ti6Al4V alloy were selected to study the ASBs induced during HSM. The experimental steels were quenched and tempered, Ti alloys were annealed and cooled at ambient temperature, and then the materials were machined into disc parts. The orthogonal cutting tests were performed on the high speed lathes, at the same time, the cutting forces were measured by the piezoelectric dynamometer.

The serrated chips were collected, and then the cross sections and free surfaces of the chip specimens were selected as observed surface. The chips were embedded in the Bakelite, after sanding, polishing and eroding, the microstructures of the primary shear zones were examined by optical microscope and SEM, the hardness of the ASBs was measured by the microhardness tester, and the microscopical pattern of fracture surfaces was observed by SEM and EPMA. The chip specimens for TEM analysis must be prepared separately for examining the microstructures of the ASBs. Because the chips are very thin, so it is difficult to handle and allocate its side surfaces. Thus before thinning a chip down, its top and bottom surfaces (see the illustration in Fig. 1) were first electroplated by Nickel to a certain thickness to make the specimen manageable. The specimens were then glued to a flat metal plate for grinding and polishing to a thickness of about $50 \mu \mathrm{m}$. The ASB zones in the chips were further thinned down by focused ion beam milling to a thickness suitable for TEM analysis ${ }^{[4]}$.

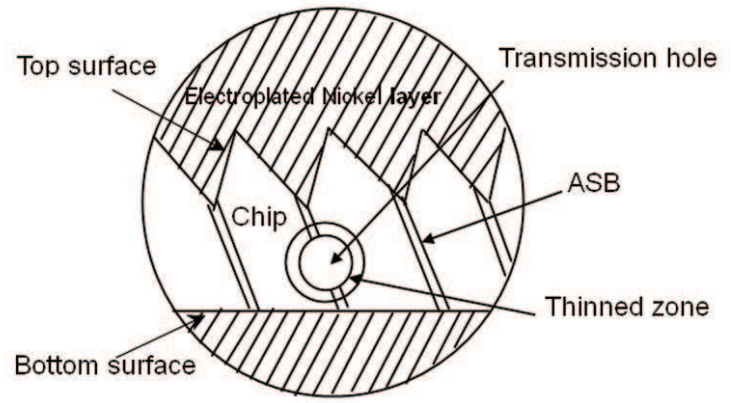

Fig. 1 Sketch map of preparation of film sample of serrated chip ${ }^{[48]}$ for TEM

\section{Results and Discussion}

\subsection{Topography and microhardness}

Localized shear deformation occurs in the primary deformation zone of the chip during cutting leading to serrated chips. The repeated ASBs with large deformation were formed between the sawtooth (see Fig. 2). Fig. 3 shows the typical SEM morphologies of the cross-section of a serrated chip. Several features deserve mention. First, the thickness of the shear 
band is not uniform, and gradually increases from the root of the sawtooth to the bottom of the chip, but fluctuates between 5 and $10 \mu \mathrm{m}$. This indicates that shear strain would correspondingly fluctuate. Second, the microstructure inside the band is much different from that outside the band. The fine grains without deformed features are observed in the center of the band, but the severely deformed and damaged structures can be seen clearly in the transitional region between the center of the band and matrix of the chip. It is reasonable that the formation process of ASB can be delved by examining the microstructural characteristics in different parts of the region between inside and outside of the band because the shear band is unlikely to generate in the case without a series of variant stages.

Microhardness measurements transverse to the shear band are shown in Fig. 4. It is seen clearly that the hardness values in and near the shear band decrease with distance from the band center until the matrix hardness is reached, and that the hardness in the center of the shear bands is higher than that of the common martensite. This implies that the material in the center of the band may be transformed into the martensite under cooling.

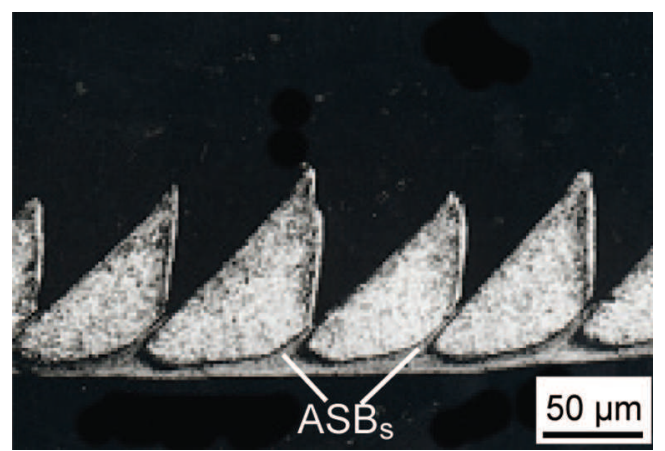

Fig. 2 A serrated chip with ASBs $(30 \mathrm{CrNi} 3 \mathrm{MoV}$ steel, cutting speed $(V)$ is $68.8 \mathrm{~m} / \mathrm{min}$, cutting depth $\left(a_{\mathrm{p}}\right)$ is $0.215 \mathrm{~mm}$, rake angle $\left(\gamma_{0}\right)$ is $\left.-10^{\circ}\right)^{[49]}$
Fig. 5 is the measured result of the microhardnesses of the ASBs formed during HSM of Ti6Al4V. The average microhardnesses outside ASBs is 400.5 $\mathrm{HV}_{0.025}$ that are close to the microhardnesses of the workpiece materials. Moreover, the microhardness outside band keeps almost unvaried with distance from the band center. It is suggested that the adiabatic shear deformation is concentrated on the narrow band and those materials outside band remain almost

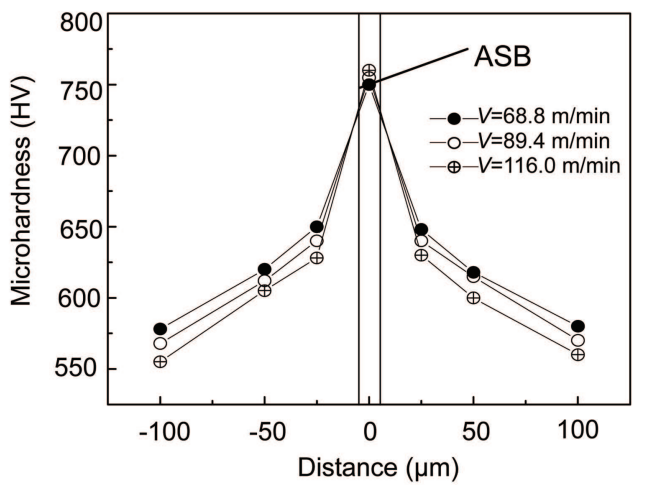

Fig. 4 Distribution of the microhardnesses acrossing the ASBs $\left(30 \mathrm{CrNi} 3 \mathrm{MoV}\right.$ steel, $a_{\mathrm{p}}=0.215 \mathrm{~mm}, \gamma_{0}=$ $\left.-10^{\circ}\right)^{[57]}$

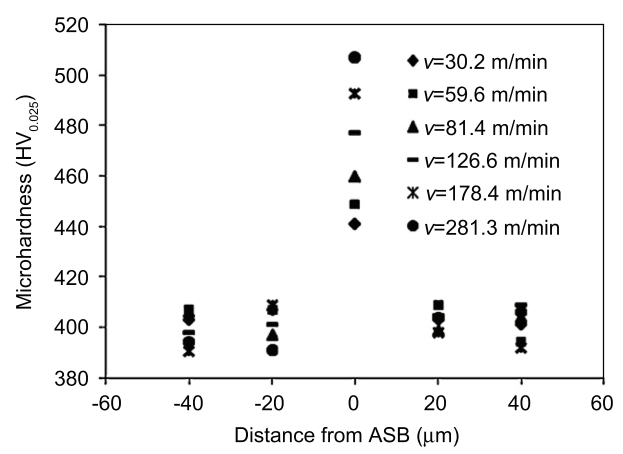

Fig. 5 Microhardness distribution acrossing ASBs under different cutting speeds (Ti6Al4V, $a_{\mathrm{p}}=0.3 \mathrm{~mm}$, $\left.\gamma_{0}=0^{\circ}\right)^{[47]}$



Fig. 3 SEM image of the ASB (a) and its magnified image (b) $(30 \mathrm{CrNi} 3 \mathrm{MoV}$ steel, $V=68.8 \mathrm{~m} / \mathrm{min}$, $\left.a_{\mathrm{p}}=0.215 \mathrm{~mm}, \gamma_{0}=-10^{\circ}\right)^{[50]}$ 
non-affected. The microhardnesses within ASBs are higher than those of outside of the bands and increases with cutting speed. The microhardnesses of ASB are $440.8 \mathrm{HV}_{0.025}$ and $448.6 \mathrm{HV}_{0.025}$ when cutting speeds are $30.2 \mathrm{~m} / \mathrm{min}$ and $59.6 \mathrm{~m} / \mathrm{min}$ respectively. The ASBs are comprised of the deformed bands when the cutting speed is or inferior to $59.6 \mathrm{~m} / \mathrm{min}$. In this case, the enhance of microhardnesses of ASBs are due to strain hardening. The microhardnesses of ASB increase from $459.6 \mathrm{HV}_{0.025}$ to $507.3 \mathrm{HV}_{0.025}$ when cutting speed increases from $81.4 \mathrm{~m} / \mathrm{min}$ to $281.3 \mathrm{~m} / \mathrm{min}$. The higher the cutting speed, the bigger the microhardness. This implies that the enhance of microhardness of ASBs is due to phase transformation hardening.

\subsection{Deformed shear band and transformed shear band}

Fig. 6 and Fig. 7 show that as the cutting speed increases (from 240.3 to $432.6 \mathrm{~m} / \mathrm{min}$ ), serrated chipping took place during HSM of AISI 1045 steel. The ASBs appear regularly in the primary shear zones between the sawteeth. The ASBs are of two types based on their different microstructural features. One of them (Fig. 6) has a highly localized straining zone with a width of about $50 \mu \mathrm{m}$. In this zone, however, the material has shown no sign of a phase change, but has experienced severe plastic shear with a high

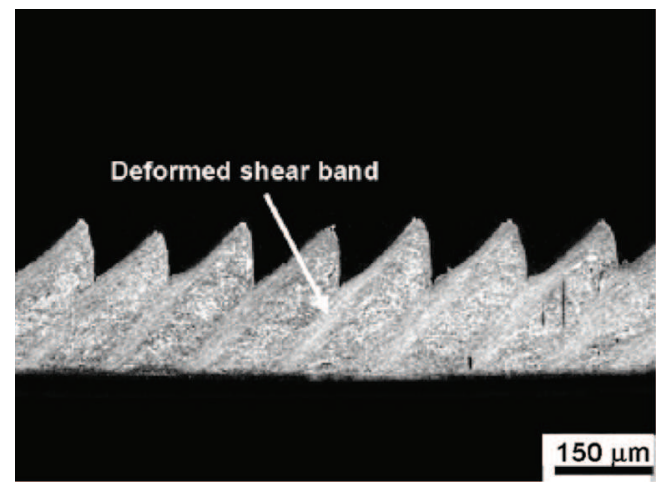

Fig. 6 OM image of the serrated chip with deformed shear bands (AISI 1045 steel, $V=240.3 \mathrm{~m} / \mathrm{min}$, $\left.a_{\mathrm{p}}=0.15 \mathrm{~mm}, \gamma_{0}=-10^{\circ}\right)^{[48]}$

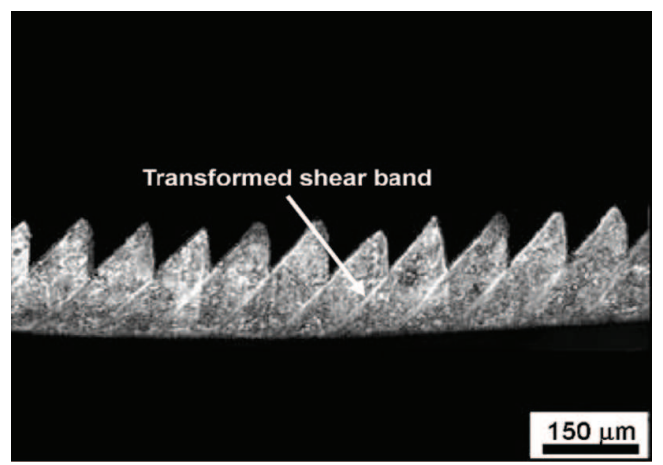

Fig. 7 OM image of the serrated chip with transformed shear bands (AISI 1045 steel, $V=432.6 \mathrm{~m} / \mathrm{min}$, $\left.a_{\mathrm{p}}=0.15 \mathrm{~mm}, \gamma_{0}=-10^{\circ}\right)^{[48]}$ density of slip lines. Therefore, this type of ASBs is the deformed shear bands. The second type of the ASBs observed (Fig. 7), of about $10 \mu \mathrm{m}$ in width, shows bright, smooth and white bands of morphology after erosion. The materials within the bands have distinct characteristics of microstructural change during the adiabatic temperature rise. These are therefore the transformed shear bands. It is worth noting that the deformed shear bands formed under lower cutting speeds (e.g., $V=240.3 \mathrm{~m} / \mathrm{min}$ ), but the transformed shear bands emerged under higher cutting speeds (e.g., $V=432.6 \mathrm{~m} / \mathrm{min}$ ), indicating that the deformed and transformed shear bands occurred under different strain rates when the other cutting conditions are the same.

Fig. 8 and Fig. 9 are SEM micrographs showing the details of the ASBs in Fig. 6 and Fig. 7, respectively. In Fig. 8, it can be seen that there is not a clear boundary between the deformed band and the surrounding material. The microstructure in the ASB is clearly elongated along the shear direction, indicating that the material in the deformed band experienced a large plastic deformation. Approaching the center of ASB, the glide lines become denser. This suggests that deformation in the center is much severer. The formation mechanism of such microstructures can

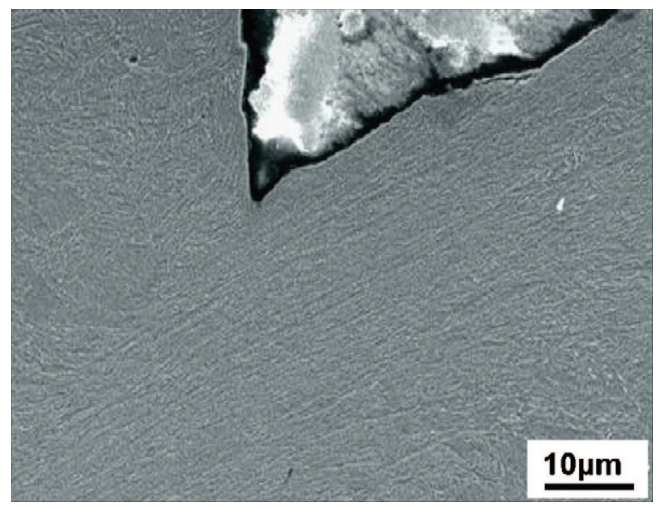

Fig. 8 SEM image of a deformed shear band (AISI 1045 steel, $V=240.3 \mathrm{~m} / \mathrm{min}, a_{\mathrm{p}}=0.15 \mathrm{~mm}, \gamma_{0}=$ $\left.-10^{\circ}\right)^{[48]}$

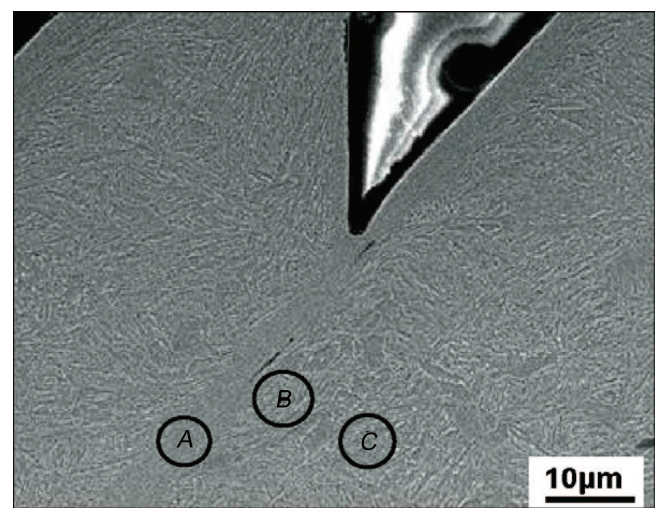

Fig. 9 SEM image of a transformed shear band(AISI 1045 steel, $V=432.6 \mathrm{~m} / \mathrm{min}, a_{\mathrm{p}}=0.15 \mathrm{~mm}, \gamma_{0}$ $\left.=-10^{\circ}\right)^{[48]}$ 
be described as follows. Due to high strain hardening effect, a great number of mobile dislocations are initiated and accumulated during the HSM in the primary shear zone to produce the deformed bands. As a result, the deformed band contains elongated and broken microstructures, but without a phase change because the local adiabatic temperature rise is insufficient at a low cutting speed. However, a transformed shear band (Fig. 9) has a well-defined width of the distinct boundaries, indicating a different formation mechanism from that of the deformed band. An important feature is that the microstructure change from the band center to the surrounding chip material can be divided into three obvious zones, marked by $A, B$ and $C$ in Fig. 9, where $A$ represents the central zone of the band, $C$ is the surrounding chip material, and $B$ is the transitional zone from $A$ to $C$. It is clear that the chip material (i.e., the material in zone $C$ ) experienced very little deformation and keeps almost its original structure. In the transitional zone $B$, the grains are elongated along the shear direction, which is similar to the characteristic in the deformed band mentioned above, and implying that the microstructure in the transitional zone can be an intermediate stage during the sequence of microstructural rearrangements leading to the transformed band. In the central zone $A$, the microstructure of the material becomes quite different, showing very fine non-deformed structures as the result of localized sever shear and grain refinement.

The similar results to hardened steels were observed during HSM of Ti6Al4V. At low cutting speed, only the incipient separation of the segments is presented as shown in Fig. 10. Increasing cutting speed to $59.6 \mathrm{~m} / \mathrm{min}$ leads to complete separation of segments and serrated chips form as shown in Fig. 11. Fig. 12 shows the microstructure pattern change of ASB with increasing of the cutting speed. In Fig. $12(\mathrm{a})$, slipping deformation which is the precursors of ASB can be observed. At the low cutting speed of $30.2 \mathrm{~m} / \mathrm{min}$, the instability is weak, and shear localization is not as sharp as that of high speed. With increasing of the cutting speed, the ASB can be observed obviously as shown in Fig. 12(b). Furthermore, it can be seen from Fig. 12(b) that the structure in the shear band is elongated along the shear

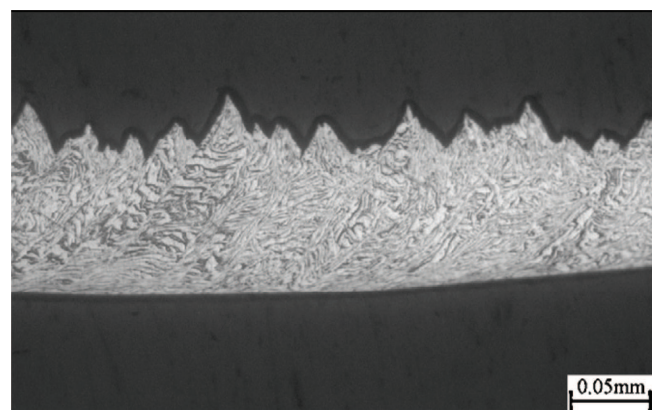

Fig. 10 Incipient separation of the segments (Ti6Al4V, $\left.V=30.2 \mathrm{~m} / \mathrm{min}, a_{\mathrm{p}}=0.3 \mathrm{~mm}, \gamma_{0}=0^{\circ}\right)^{[47]}$

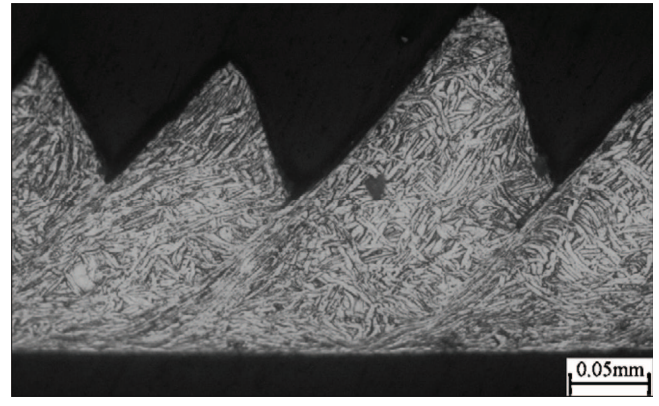

Fig. 11 Complete separation of segments (Ti6Al4V, $(V=$ $\left.59.6 \mathrm{~m} / \mathrm{min}, a_{\mathrm{p}}=0.3 \mathrm{~mm}, \gamma_{0}=0^{\circ}\right)^{[47]}$

direction and underwent an extremely high deformation. When the cutting speed increases to $81.4 \mathrm{~m} / \mathrm{min}$, the pattern in the center of ASB obviously differs from that of the boundary of ASB and the structure in the center is too dense to distinguish on optical microscope (Fig. 12(c)). When the cutting speed reaches $126.6 \mathrm{~m} / \mathrm{min}$, the refined structure in the center of ASB becomes more obvious (Fig. 12(d)). Fig. 12(e) presents the morphology of ASB when the cutting speed increases to $178.4 \mathrm{~m} / \mathrm{min}$. As shown in Fig. 12(e), the fiber structures on the boundary of ASB have to be extremely thin even that they are recognized by the optical microscope. The ASBs have marked boundaries with matrix. It is shown that the changes only occurred inside ASB and the outside of ASB remained almost non-affected. Fig. 12(f) shows the microstructure of ASB obtained at cutting speed up to $281.3 \mathrm{~m} / \mathrm{min}$, the ASB is composed of transformed ASB completely.

\subsection{Phase transformation}

Fig. 13 shows the result of elemental analysis within and near the ASB produced during HSM of $30 \mathrm{CrNi} 3 \mathrm{MoV}$ steel. Fig. 13 (a) is a secondary electron image of the ASB, there is obvious limit between the ASB and the chip matrix. The shear band shows a flat and smooth morphology, indicating that the ASB has strong corrosion resistance due to very small grains. A lot of uneven corroded pits are displayed in the matrix materials located both sides of the ASB, indicating that there are obvious difference between the ASB and the matrix in microstructure. Fig. 13 (b) is an absorption electron image of Fig. 13(a), showing the distribution of chemical composition in this region, the composition fluctuation within the ASB is small, this indicating that under the combined action of adiabatic temperature rise and high-speed deformation, the redistribution of chemical element occurred among the constituent phases during the formation of ASB. However, since the time of redistribution is very short, the composition float between the ASB and matrix cannot be produced, indicating that although the ASB had experienced high temperature and large deformation, but the difference in the composition between the shear band and the matrix is not evident. Fig. 13(c) and Fig. 13(d) show the distributions of $\mathrm{C}$ and $\mathrm{Cr}$ in the observated area respectively. 

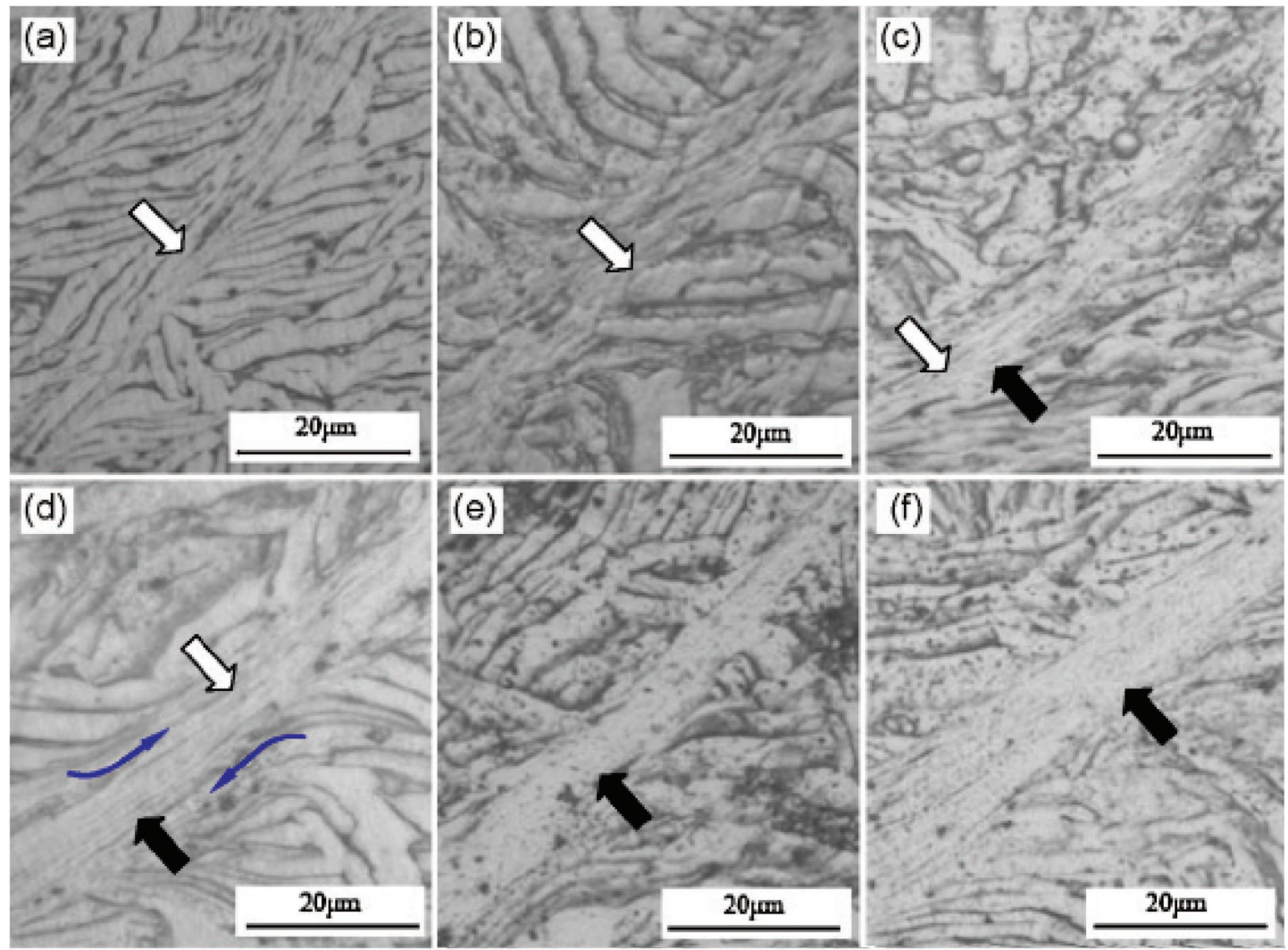

$\Rightarrow$ Deformed band

Transformed band

Fig. 12 Shear bands' micro-features of the serrated chips obtained with different cutting speed: (a) $30.2 \mathrm{~m} / \mathrm{min}$; (b) $59.6 \mathrm{~m} / \mathrm{min}$; (c) $81.4 \mathrm{~m} / \mathrm{min}$; (d) $126.6 \mathrm{~m} / \mathrm{min}$; (e) $178.4 \mathrm{~m} / \mathrm{min}$; and (f) $281.3 \mathrm{~m} / \mathrm{min}\left(\mathrm{Ti} 6 \mathrm{Al} 4 \mathrm{~V}, a_{\mathrm{p}}=0.3 \mathrm{~mm}, \gamma_{0}=0^{\circ}\right)^{[47]}$
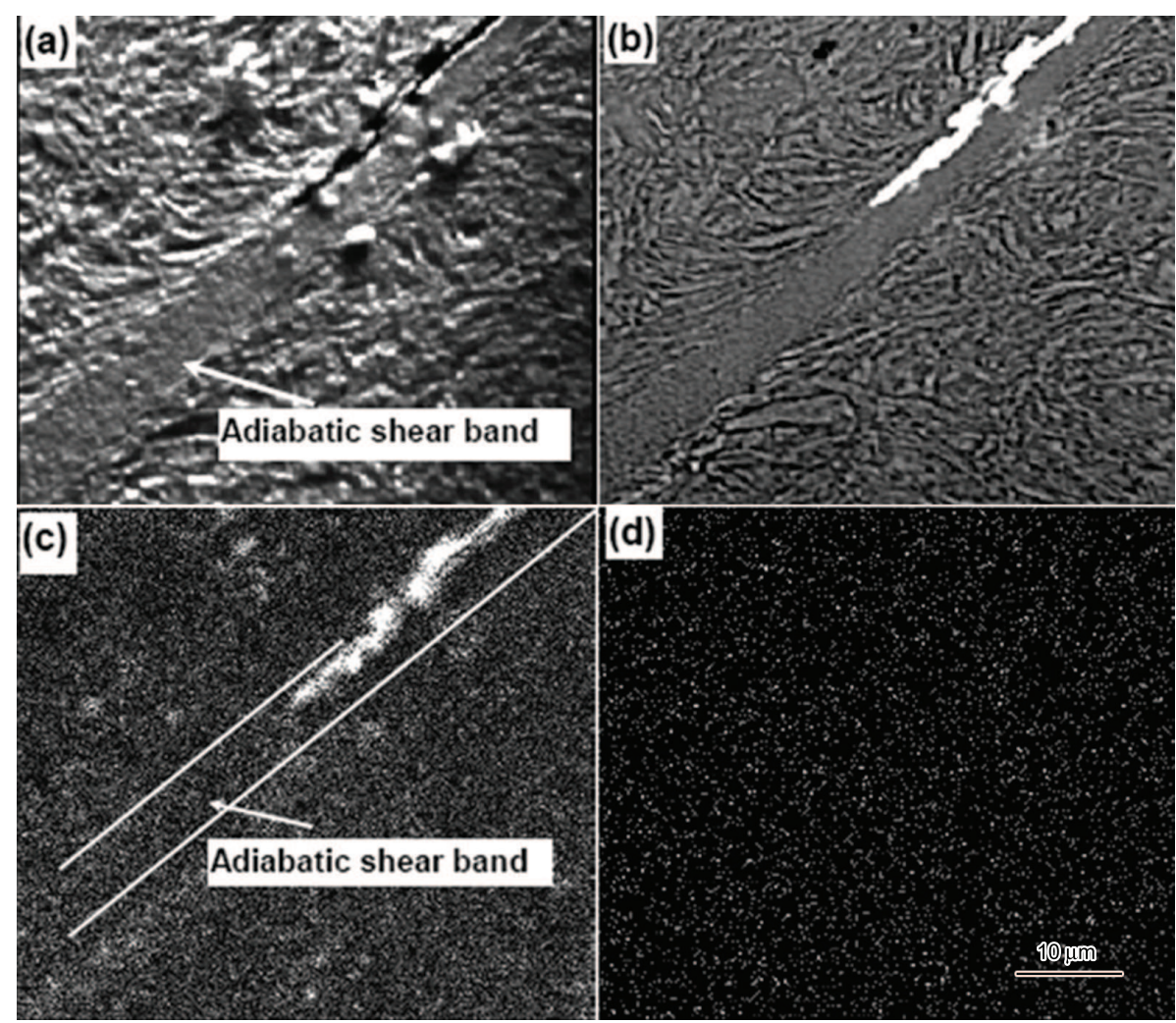

Fig. 13 EPMA area scanning images showing the distribution of chemical element near the ASB: (a) secondary electron image of surface; (b) absorption electron image corresponding to Fig. 13(a); (c) distribution of C; (d) distribution of $\mathrm{Cr}\left(30 \mathrm{CrNi} 3 \mathrm{MoV}\right.$ steel, $V=298.5 \mathrm{~m} / \mathrm{min}, a_{\mathrm{p}}=0.215 \mathrm{~mm}, \gamma_{0}$ $\left.=-10^{\circ}\right)^{[52]}$ 
In Fig. 13 (c), the distribution of $\mathrm{C}$ is generally uniform in whole observation area, but the distribution of white spots within the ASB marked in this figure is more uniform, and the brightness is slightly darker, indicating that the short-distance diffusion of $\mathrm{C}$ may occur during the formation of ASB. Carbon element segregated in the interface between the shear band and matrix, resulting in slight decrease of $\mathrm{C}$ content within the ASB. In the whole observated area, the evident element segregation cannot be found showing that long-range diffusion for any element is impossible. Fig. 13(d) shows the result of surface analysis for $\mathrm{Cr}$ elements also, the distribution of $\mathrm{Cr}$ elements is very uniform, there is not any segregation phenomenon, indicating that there is no generation of new alloy carbides during ASB formation. The composition analysis of carbon shows that the diffusion and gather of carbon may occur during formation of ASB. The diffusion mechanism may be short-range diffusion driven by high-speed deformation and high temperature rise.

Fig. 14 shows the TEM micrographs of the trans- formed ASB produced during HSM of $30 \mathrm{CrNi} 3 \mathrm{MoV}$ steel. The equiaxed structure is shown in Fig. 14(a), no grain boundaries can be resolved. As a result, a large number of Moire fringes were observed in the sample. No deformation twins or martensite laths were observed in the ASB. Some carbides particles can be revealed between the microstructures. The above observed results indicate that dynamic recrystallization may take place in the center of the ASB. The large amount of dislocations disappeared due to the climb and the merging of dislocations under adiabatic temperature rise. The selected area electron diffraction pattern is shown in Fig. 14(b). The reflections of multiple grains formed discontinuous rings. The indexing of the electron diffraction pattern from central region reveals that the microstructure contains martensite, $\mathrm{Fe}_{3} \mathrm{C}$ and $\chi-\mathrm{Fe}_{5} \mathrm{C}_{2}$ carbides, and austenite. The results of the indexing of the diffraction pattern are presented in Table 1 . These results are similar to those obtained by Wittman and Meyers ${ }^{[63,64]}$, however, they had not found martensite in the ASB. The occurrence of the microstructure in Fig. 14 (a)

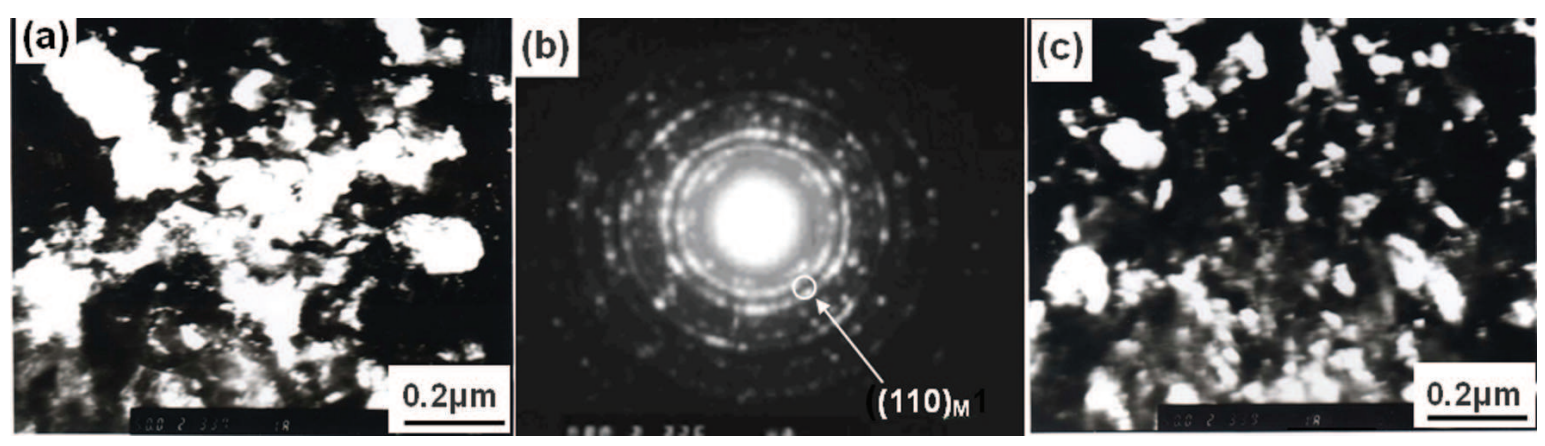

Fig. 14 TEM micrographs of the transformed ASB: (a) BF image show the dynamic recrystallization structure; (b) diffraction pattern; (c) DF image from the $(110)_{\mathrm{M}}$ martensite reflection $(30 \mathrm{CrNi} 3 \mathrm{MoV}$ steel, $\left.V=298.5 \mathrm{~m} / \mathrm{min}, a_{\mathrm{p}}=0.215 \mathrm{~mm}, \gamma_{0}=-10^{\circ}\right)^{[49,50]}$

Table 1 Experimental interplanar distance (nm) obtained from the diffraction pattern of the center region in the transformed ASB and that of different phases ${ }^{[49,50]}$

\begin{tabular}{|c|c|c|c|c|}
\hline Experimental & Martensite & $\mathrm{Fe}_{3} \mathrm{C}$ & $\chi-\mathrm{Fe}_{5} \mathrm{C}_{2}$ & Austenite \\
\hline 0.252 & & $0.254(020)$ & $0.251(002)$ & \\
\hline 0.240 & & & $0.242(311)$ & \\
\hline 0.204 & $0.203(110)$ & & & $0.205(111)$ \\
\hline 0.176 & & $0.176(122)$ & $0.177(402)$ & $0.176(200)$ \\
\hline 0.1640 & & $0.1641(212)$ & $0.1640(421)$ & \\
\hline 0.1440 & $0.1433(200)$ & & & \\
\hline 0.1358 & & $0.135(232)$ & $0.134(023)$ & \\
\hline 0.125 & & & & $0.126(220)$ \\
\hline 0.1154 & $0.117(112)$ & & & \\
\hline 0.102 & $0.101(202)$ & & & $0.103(222)$ \\
\hline 0.094 & $0.091(103)$ & & & \\
\hline 0.0880 & & & & $0.0895(400)$ \\
\hline 0.0779 & $0.0772(213)$ & & & \\
\hline
\end{tabular}


leads to the belief that there was a significant amount of carbon in solution. The presence of $\chi-\mathrm{Fe}_{5} \mathrm{C}_{2}$ and $\mathrm{Fe}_{3} \mathrm{C}$ carbides in the central region may occur during austenitizing in the ASB. The materials in the ASB transformed to austenite owing to the adiabatic temperature rise during cutting process, rapidly quenched to martensite, and then the remaining adiabatic heat caused many carbon atoms to be precipitated at microdefects as shown by the diffraction pattern. Therefore, the martensitic phase transformation took place in the ASB. To resolve further the features of the ASB, dark field microscopy was used. Fig. 14(c) shows a dark field micrograph from the $(110)_{\mathrm{M}}$ martensite reflection. The grains are equiaxed, these small equiaxed grains vary between 50 and $100 \mathrm{~nm}$ in diameter. Whilst some recrystallization grains just started to nucleate, other equiaxed grains already grew up. The dynamic recrystallization and phase transformation are almost simultaneous due to the very short time in the formation process of ASB.

Fig. 15 shows TEM images of ASBs formed during HSM of Ti6Al4V. From Fig. 15(a), the center of ASB is composed of nanocrystalline at the cutting speed of $126.6 \mathrm{~m} / \mathrm{min}$, The multiple electron diffractions rings can be indexed with both $\alpha$ and $\alpha^{\prime \prime}$ phases as the dspacing dot where the two phases are almost superimposed. The multiple electron diffraction rings can be indexed with lattice parameters of two phases, $\alpha$ and $\alpha^{\prime \prime}$. The interplanar distances for two phases are very close, and it is difficult to distinguish them, thus multiple electron diffraction rings can form as shown in Fig. 15(a). As $\beta$ phase cannot be seen in this diffraction pattern, it is possible that the $\beta$ phase transformed into $\alpha^{\prime \prime}$ phase and martensitic phase transformation has occurred. Fig. 15(b) shows corresponding TEM image of ASB at the cutting speed of $281.3 \mathrm{~m} / \mathrm{min}$. As shown in the insert in Fig. 15(b) the electron diffraction pattern shows amorphous disk in the pattern center as well as bright diffraction spot and rings departure the center. It indicates that very fine crystalline phases and a small amorphous area are presented simultaneously, and these confirmed further the observations by Meyers and $\mathrm{Xu}^{[71-72]}$ who found the transition of crystalline lattice to the nanocrystals and amorphous structure in the shear bands under high-strain rate loading in Fe-Cr-Ni monocrystal. The results make it clear that the ASB is composed of transformed ASB.

\subsection{Microstructural evolution}

In the experiments, the gradient microstructures often were observed within and near the ASBs. From Figs. 16-20, there are TEM images of the ASB in the serrated chip produced in HSM of hardened AISI 1045 steel. Fig. 16 shows the microstructure of surrounding chip material near the ASB, the original martensite laths are confirmed by the bright field image as seen in Fig. 16(a), the corresponding diffraction pattern in Fig. 16(b) shows a regular diffraction lattice of [111] zone axis of the martensite. Dislocations distribute inside and between the laths. A few twins also appear within the laths. These demonstrate that dislocation slipping is a main mechanism of plastic deformation because of the relatively lower strain and strain rate levels that the materials experienced in this zone. Fig. 17 and Fig. 18 show the microstructures of the materials in the transitional zone in the ASB. Fig. 17(a) displays the lath structure of the material at a point away from the band center. It can be seen that these laths are intensely elongated along the shear direction. The dislocations are mostly at the lath boundaries. Inside the laths the dislocation density is relatively low and the slip traces are distributed homogeneously. The deformation in this zone is clearly not severe, and hence the dislocation density is not high. The diffraction pattern in

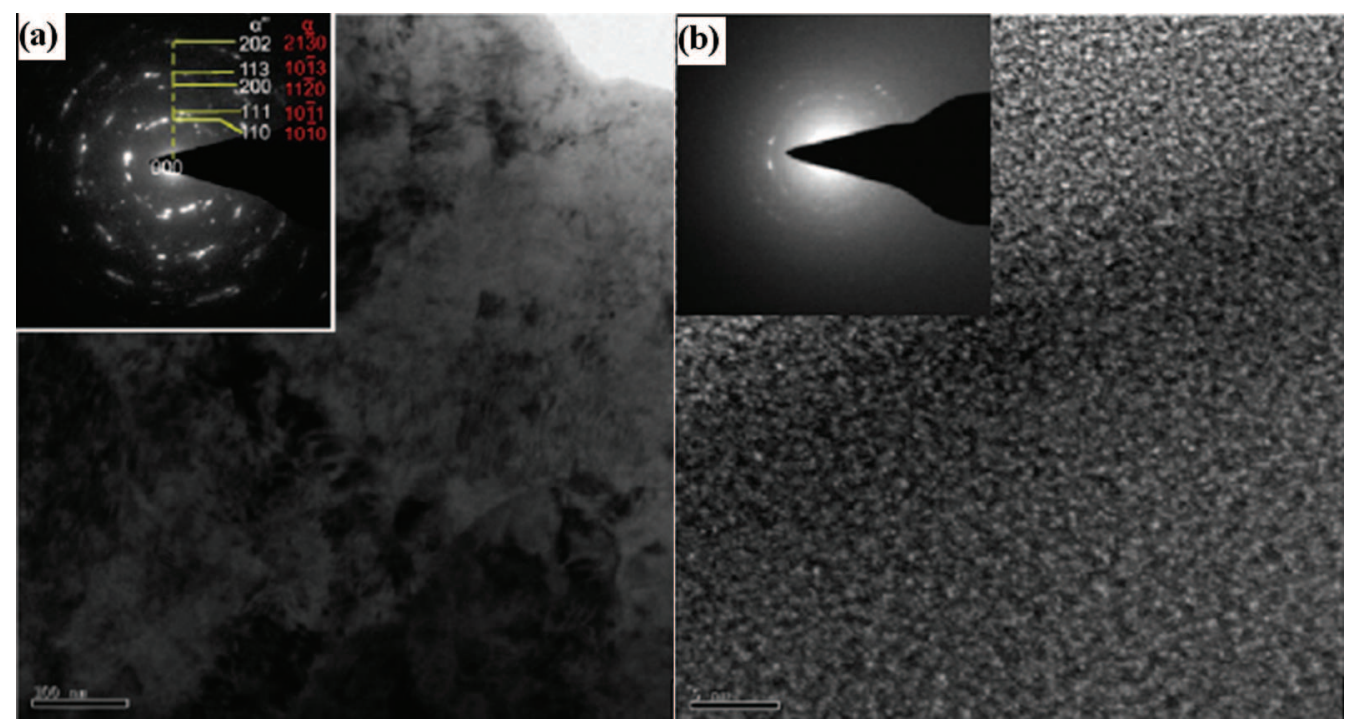

Fig. 15 TEM images of ASBs formed during HSM of Ti6Al4V: (a) $V=126.6 \mathrm{~m} / \mathrm{min}$; (b) $V=281.3 \mathrm{~m} / \mathrm{min}$ $\left(a_{\mathrm{p}}=0.3 \mathrm{~mm}, \gamma_{0}=0^{\circ}\right)^{[47]}$ 


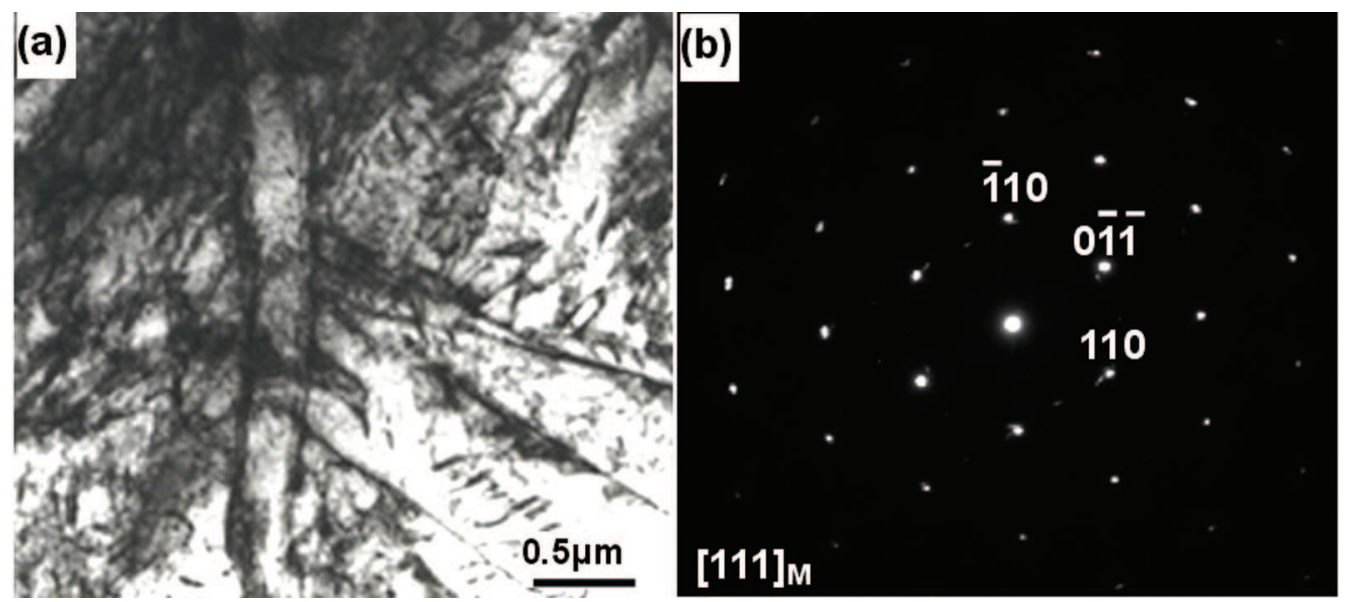

Fig. 16 TEM images of surrounding chip material near the ASB: (a) the bright field image showing the common martensite laths: (b) the corresponding SAED pattern (AISI 1045 steel, $V=432.6 \mathrm{~m} / \mathrm{min}$, $\left.a_{\mathrm{p}}=0.15 \mathrm{~mm}, \gamma_{0}=-10^{\circ}\right)^{[48]}$

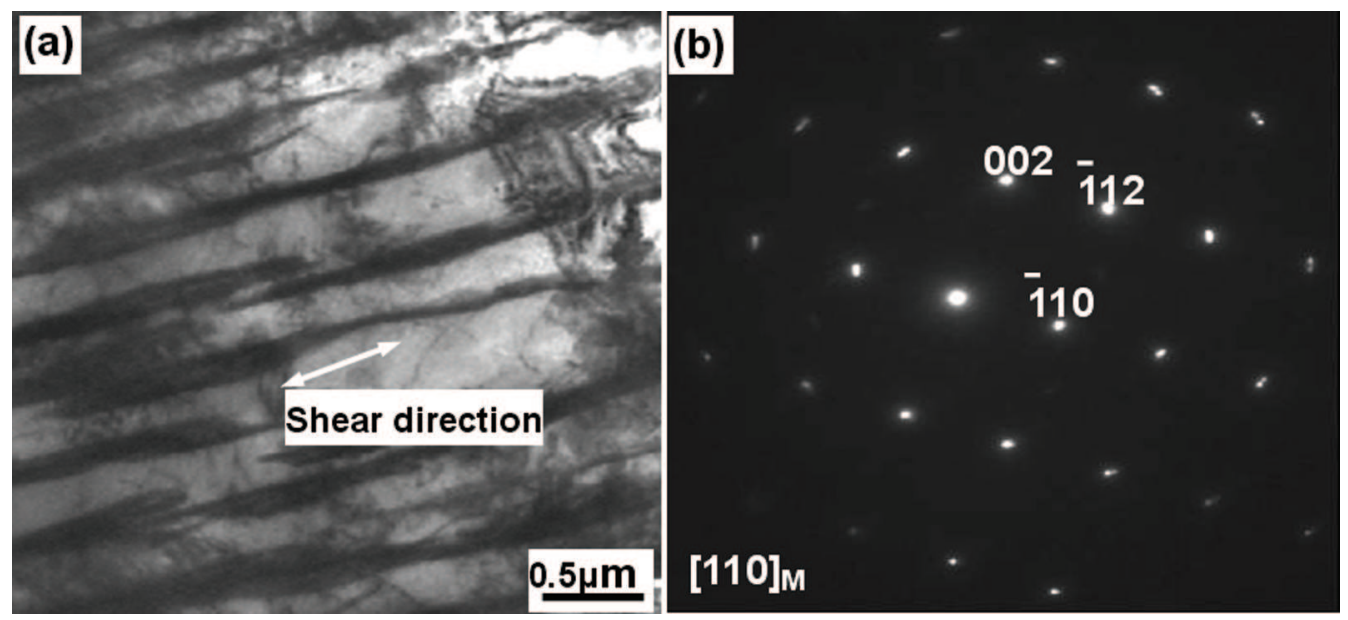

Fig. 17 TEM images of the material in the transitional zone in the ASB: (a) the bright field image showing the severely elongated martensite laths along the shear direction; (b) the corresponding SAED pattern. (AISI 1045 steel, $\left.V=432.6 \mathrm{~m} / \mathrm{min}, a_{\mathrm{p}}=0.15 \mathrm{~mm}, \gamma_{0}=-10^{\circ}\right)^{[48]}$



Fig. 18 TEM images of the material in the transitional zone but near the center the ASB: (a) the bright field image showing the martensite laths divided by dislocations; (b) the corresponding SAED pattern (AISI 1045 steel, $\left.V=432.6 \mathrm{~m} / \mathrm{min}, a_{\mathrm{p}}=0.15 \mathrm{~mm}, \gamma_{0}=-10^{\circ}\right)^{[48]}$ 

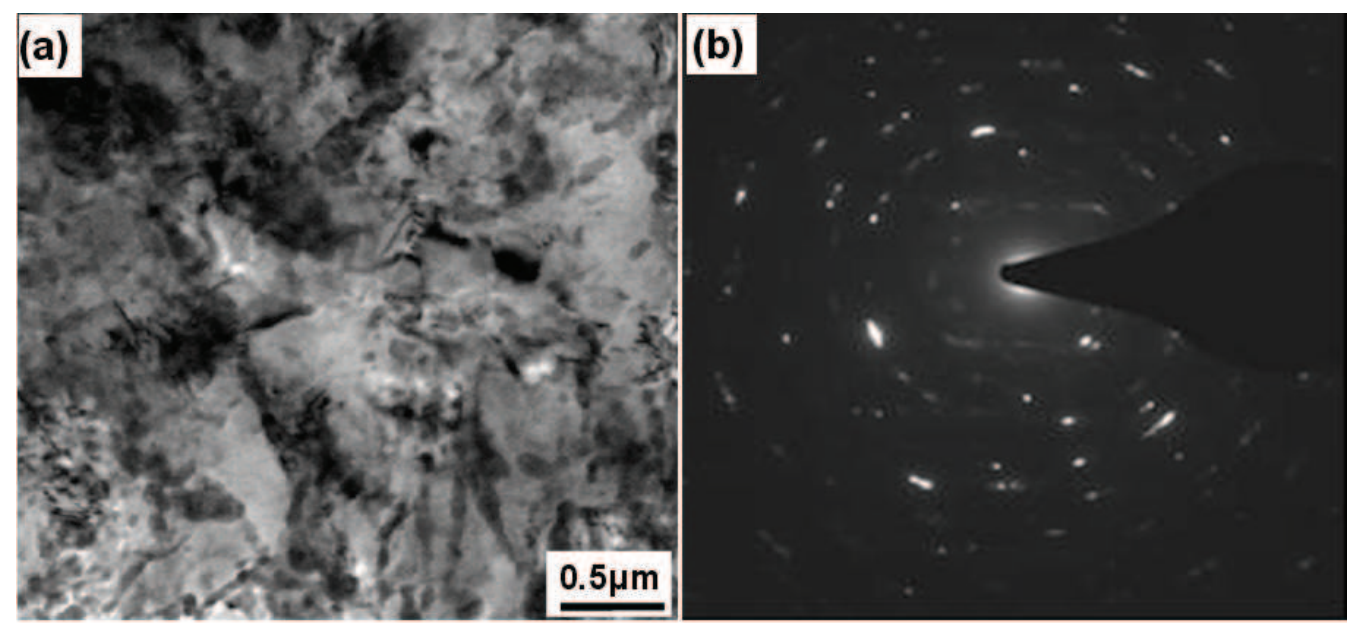

Fig. 19 TEM images of the central zone close to transitional zone in the ASB: (a) the bright field image showing the subgrain structure; (b) the corresponding SAED pattern (AISI 1045 steel, $V=$ $\left.432.6 \mathrm{~m} / \mathrm{min}, a_{\mathrm{p}}=0.15 \mathrm{~mm}, \gamma_{0}=-10^{\circ}\right)^{[48]}$
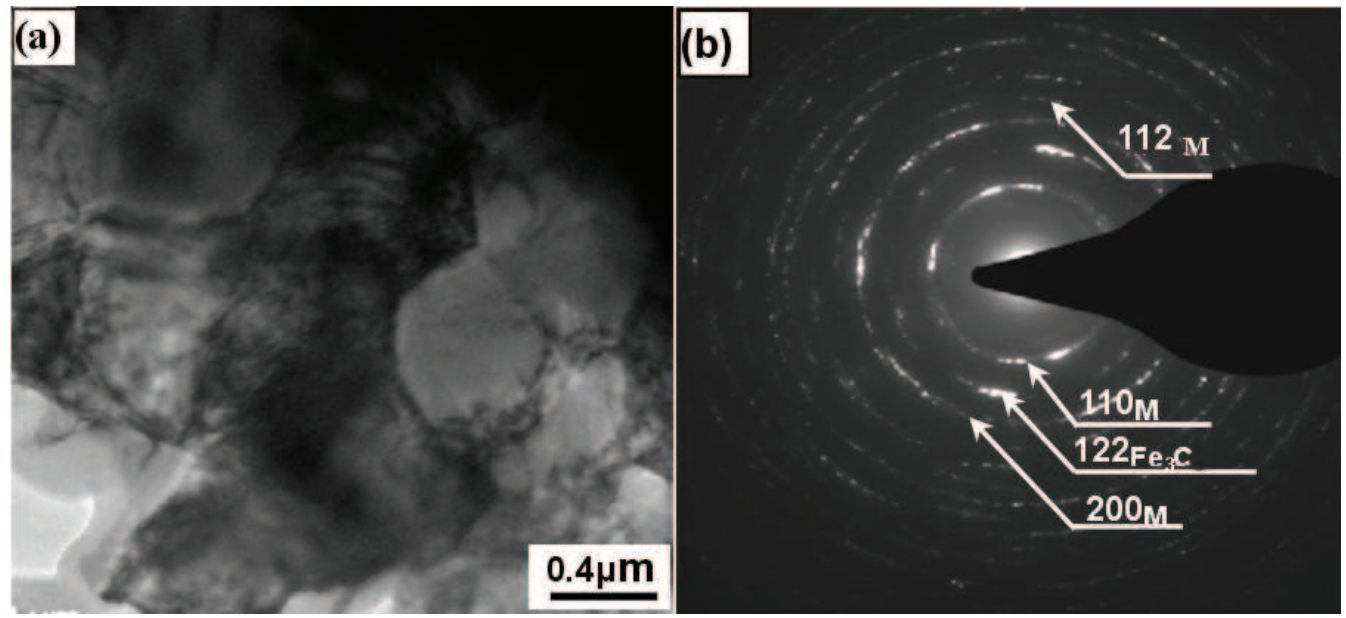

Fig. 20 TEM images of the material at the center of the ASB: (a) the bright field image showing the equiaxed grains; (b) the corresponding SAED pattern showing the polycrystalline diffraction rings. (AISI 1045 steel, $\left.V=432.6 \mathrm{~m} / \mathrm{min}, a_{\mathrm{p}}=0.15 \mathrm{~mm}, \gamma_{0}=-10^{\circ}\right)^{[48]}$

Fig. 17(a) shows that the microstructure of the material in this zone is a tempered martensite structure. On the other hand, the materials in the transitional zone adjacent to the band center of the ASB contain broken and elongated martensite laths in the shear direction, as shown in Fig. 18(a). A large number of dislocation tangles exist between the transitional zone and inside the laths. The areas which have high dislocation densities divide the elongated laths into many smaller sub-regions. The diffraction spots are slightly elongated, as shown by Fig. 18(b), indicating that the material is subjected to a larger plastic deformation, but its crystallography structure is retained and no phase change took place because the recrystallization temperature in this zone did not reached. Figs.19 and 20 display the microstructure of the material in the central zone. The material in the area close to the transitional zone contains many subgrains with a high density of dislocations. The lath morphology disappears, which is similar to the recovery structure under thermal deformation, as shown in Fig. 19(a). The diffraction pattern changes from the regular lattice to discontinuous rings shown in Fig. 19 (b). Fig. 20 shows that the material at the center of the ASB contains many equiaxed grains. The dislocation density in such grains is relatively low. These grains, however, have a high angle of misorientation, and are similar to the structure of recrystallization, although their sizes are smaller than that of the statically recrystallized grains, as shown in Fig. 20(a). The ring-like electron diffraction pattern with intermittent spots, Fig. 20(b), demonstrates that these grains are of polycrystalline with random orientations. The indexing of the polycrystalline diffraction rings shows that these equiaxed grains are composed of martensite and cementite without residual austenite, indicating that a phase transformation should not have occurred there.

The above findings provide a better understanding of mechanism of microstructural evolution during the formation of ASB. From the external of an ASB 
to its center, the material experiences a variation of strain and strain rate. The microstructures observed in different zones indirectly reflect the microstructural evolution stages in an ASB. We can therefore propose an evolution picture, as illustrated in Fig. 21, to interpret what could have happened within an ASB during HSM of the steel. First, when the cutting operation just begins, the tempered martensite in an originaly heat treated workpiece is subjected to a high strain rate deformation. A large number of dislocations start to emit. However, due to the relative low plastic strain at this stage, the morphology of the martensite laths remains, as shown in Fig. 16 and Fig. 21(a). As the deformation proceeds, adiabatic shear is triggered and the dislocation density increases sharply. The serious plastic slips cause the reorientation and elongation of the lath structure along the shear direction, as shown in Fig. 17 and Fig. 21(b). With the enhancement of the deformation localization, the dislocations begin to climb forming the dislocation cells. In the area, under a high strain rate, even at a very low temperature, the cell structure formation by dislocation climbing is very strong. The local temperature also rises rapidly. Because of this, the concentration and tangle of dislocations begin to form the areas with high and low dislocation densities and eventually give rise to subboundaries. These subgrain cell walls are then segmented and the elongated laths refined, as shown in Fig. 18 and Fig. 21(c). As the deformation continues, many dislocations disappear due to their climbing and merging under adiabatic temperature rise, which is a process of dynamic recovery leading to subgrains with high dislocation density as seen in Fig. 19 and illustrated in Fig. 21(d). To coordinate further deformation with the increase of strain and strain rate, these refined subgrains assisted with the adiabatic temperature rise polygonally to form the equiaxed and randomly oriented recrystallized grains, as shown in Fig. 21(e). Finally, the recrystallization-induced residual stress may introduce further dislocations to form the substructures in the equiaxed grains, as illustrated in Fig. 21(f), but the dislocation density is relatively low as revealed by Fig. 20 .

\subsection{Recrystallization mechanism}

Based on the analysis mentioned above, it is reasonable to infer that the fine equiaxed grains obtained in the centers of ASBs within the serrated chips are the result of recrystallization. Temperature is one of the main factors that determine the possibility of recrystallization. In general, for a metallic material, the recrystallization temperature ranges from $0.4 T_{\mathrm{m}}$ to $0.5 T_{\mathrm{m}}$, where $T_{\mathrm{m}}$ is the melting point of the material. For AISI 1045 steel, $T_{\mathrm{m}}=1350{ }^{\circ} \mathrm{C}$, which means that the recrystallization temperature of the material is between $540{ }^{\circ} \mathrm{C}$ and $675{ }^{\circ} \mathrm{C}$. In order to see if this recrystallization temperature either reached or not in the ASBs of workpiece material, the temperature rise should be estimated. The adiabatic temperature rise $\Delta T$ within an ASB during deformation localization can be calculated by ${ }^{[65]}$ :

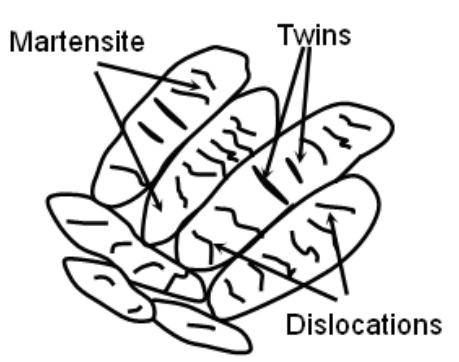

(a)

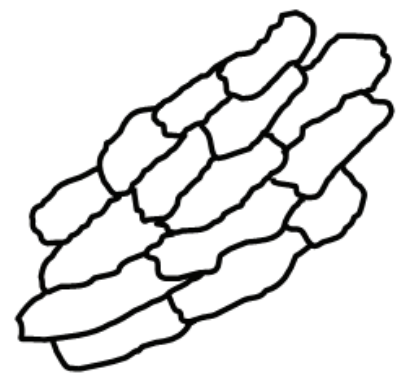

(d)

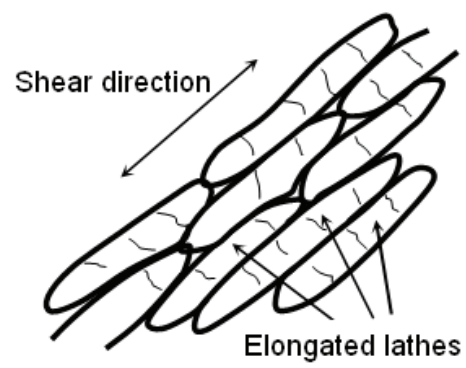

(b)

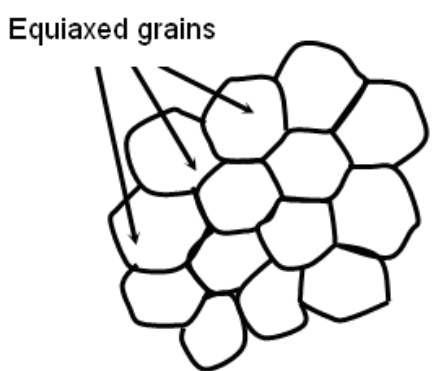

(e)

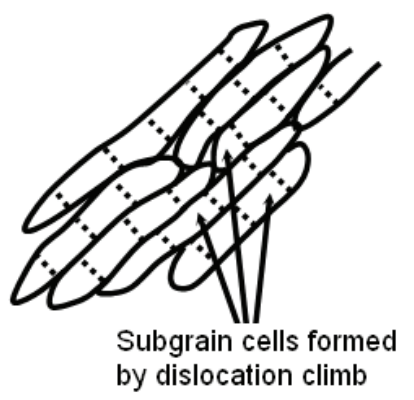

(c)

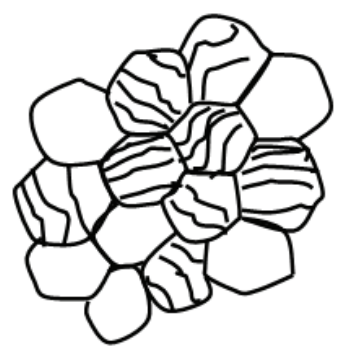

(f)

Fig. 21 Illustrative description of the microstructural evolution of the material in an ASB during the HSM of hardend steel: (a) initial microstructure; (b) reorientation and elongation of martensite laths along the shear direction; (c) partitioning of elongated subgrains; (d) formation of subgrains with a high density of dislocations; (e) formation of the equiaxed grain structure; (f) formation of the substructure in equiaxed grains ${ }^{[48,54]}$ 


$$
\Delta T=\frac{k \gamma \tau}{\rho c}
$$

where $k$ is a constant $(0.9$, i.e., about $90 \%$ of the deformation energy converted into heat), $\gamma$ is the shear strain, $\tau$ is the average shear stress, $\rho$ and $c$ are the material density and the heat capacity, respectively. The average shear stress in an ASB for orthogonal cutting is given by ${ }^{[49]}$

$$
\tau=\frac{\sin \beta \cdot\left[F_{c} \cdot \sin \left(\beta-\gamma_{0}\right)-F_{T} \cdot \cos \left(\beta-\gamma_{0}\right)\right]}{\left(H-\frac{h}{2}\right) \cdot a_{w}}
$$

where $F_{\mathrm{c}}$ and $F_{\mathrm{T}}$ are the cutting and thrust forces, $\beta$ is the included angle between the shear band and the bottom of the chip, $\gamma_{0}$ is the tool rake angle, $H$ is the height of the chip, $h$ is the height of the sawtooth, $a_{\mathrm{w}}$ is the cutting width. The average shear strain $\varepsilon$ in the ASB in orthogonal cutting is ${ }^{[4]}$ :

$$
\varepsilon=\frac{h \cdot \sqrt{H^{2}+a_{c}^{2}-2 H \cdot a_{c} \sin \gamma_{0}}}{H \cdot w \cdot \cos \gamma_{0}}
$$

where $a_{\mathrm{c}}$ is the cutting thickness and $w$ is the shear band width. All parameters are known or can be obtained by measurement. For the AISI 1045 steel, $\rho=7.8 \times 10^{3} \mathrm{~kg} / \mathrm{m}^{3}, c=474 \mathrm{~J} /\left(\mathrm{kg} \cdot{ }^{\circ} \mathrm{C}\right)$. When the cutting speed $V=240.3 \mathrm{~m} / \mathrm{min}$, the calculated temperature rise within the deformed shear band is about $360{ }^{\circ} \mathrm{C}$, which is below of the recrystallization temperature range for this material, showing that recrystallization could not occur. This explains the reason of the formation of the deformed shear bands under this cutting speed as revealed in the previous sections. When the cutting speed increases $432.6 \mathrm{~m} / \mathrm{min}$, the calculated temperature in the transformed band is approximately $1290{ }^{\circ} \mathrm{C}$ which is very much beyond the recrystallization temperature range, and also exceeds the Austenitization temperature (which is $727{ }^{\circ} \mathrm{C}$ for AISI 1045 steel in the equilibrium Fe-C phase diagram). However, because of the extremely short time in HSM, austenitization cannot take place. This is consistent with what were observed in the experiments, i.e., only recrystallization takes place.

Another crucial factor to influence recrystallization is time. According to this, recrystallization can be divided into two categories: static recrystallization and dynamic recrystallization, of which the former often occurs after deformation while latter takes place almost simultaneously with the deformation process. If the cooling rate in an ASB does not exceed the formation speed of the ASB, the recrystallization inside the ASB should be a dynamic recrystallization. The cooling rate of ASB in medium carbon steel estimated by Wittman et al.$^{[63]}$ is $10^{6} \mathrm{~K} / \mathrm{s}$. According to this, for AISI 1045 steel, when the temperature rise in the ASB is $1290{ }^{\circ} \mathrm{C}$ under the cutting speed of $432.6 \mathrm{~m} / \mathrm{min}$, the time required to cool it to room temperature should be about $0.7 \mathrm{~ms}$. The strain rate $\dot{\varepsilon}$ in the ASB during the serrated chip formation is ${ }^{[50]}$

$$
\dot{\gamma}=\frac{\varepsilon \cdot V \cdot \cos \gamma_{0} \cdot \cos \left(\alpha-\gamma_{0}\right)}{\left(L \cos \gamma_{0}+a_{\mathrm{c}}\right) \cdot \sin \alpha-H \cdot \cos \left(\alpha-\gamma_{0}\right)}
$$

Thus, the formation time of the ASB $\left(t_{\mathrm{ASB}}\right)$ is

$$
t_{\mathrm{ASB}}=\frac{\left(L \cos \gamma_{0}+a_{\mathrm{c}}\right) \sin \alpha-H \cdot \cos \left(\alpha-\gamma_{0}\right)}{v \cos \gamma_{0} \cdot \cos \left(\alpha-\gamma_{0}\right)}
$$

where $L$ is the spacing of the sawteeth, $\alpha$ is the included angle between rake tool face and free face of chip. For AISI 1045 steel, when $V=432.6 \mathrm{~m} / \mathrm{min}$, the calculated formation time of the ASB is approximately $0.09 \mathrm{~ms}$, which is far less than the cooling time of the ASB. Therefore, it is concluded that the recrystallization in the transformed bands during HSM is a dynamic recrystallization.

Derby ${ }^{[66]}$ divided the dynamic recrystallization mechanism into two types: grain boundary migration and grain rotation. The migrational dynamic recrystallization is governed by diffusion and developed by the way of nucleation and growth of recrystallization grains. The rotational recrystallization does not experience the nucleation and growth processes, but is completed through the self-rotation of the subgrains. The investigation from Hine and Vecchio ${ }^{[17]}$ on recrystallization kinetics in ASB of titanium and copper indicated that because the formation time of ASB is extremely short, on the order of tens of microseconds based on the strain rate of the cutting tests, the migration of the grain boundary is unlikely to occur in such a short period of time. Therefore, the recrystallization grains observed in experiments above should not be the result of migration of the boundaries. In other words, the recrystallization mechanism via grain boundary migration based on atomic diffusion should not be the case for the formation of the fine equiaxed grains in the ASBs here. Some other researchers suggested that the grain rotation based on mechanical mechanism can well explain the formation of equiaxed grain structure within an ASB. For example, Hines et al. ${ }^{[17]}$ proposed a mechanical model of subgrain rotation using the theory of crystal plasticity, they believe that the rotary recrystallization is not controlled by the diffusion mechanism of nucleation and growth, but is based on a mechanical mechanism through subgrain rotation. Therefore, it is possible that the equiaxed grains with high misorientation during HSM process are produced in a very short period of time.

Since traditional mechanism of the grain boundary migration is not able to explain the recrystallization process within an ASB, the recrystallized grain size cannot be obtained using a recrystallization kinetics equation in the form of atomic heat transfer. Under high strain rate loading, the grain size of rotational recrystallization is inversely proportional to stress level and is in line with the following relation ${ }^{[66]}$

$$
\frac{\sigma \delta}{\mu b}=K
$$

where $\sigma$ is the external stress, $\delta$ is the recrystallized grain size, $\mu$ is the elastic shear modulus, $b$ is the Burgers vector, and $K$ is a material constant (for metals 
$K \approx 10)$. This equation may be used to predict the recrystallized grain size in our ASBs induced by HSM. Using Eq. (6), the recrystallized grain size is calculated to be about $0.7 \mu \mathrm{m}$, which is close to $0.6 \mu \mathrm{m}$ of the equiaxed grains observed. This further verifies that the equiaxed grains in the center of the ASBs within the serrated chips are the products of the rotational dynamic recrystallization.

\subsection{Microscopic fracture mechanism}

To explore fracture mechanism during serrated chip formation, the microscopic pattern of fracture surfaces in the serrated chips during HSM of hardened steel was observed. Fig. 22 shows SEM images of the fracture surfaces of the serrated chip. The macrograph in Fig. 22 (a) shows two distinct regions ( $D$ and $E): D$ region displays large and rough surface, while $E$ region is characterised by flat surface. In a higher magnification micrograph of $D$ region (Fig. 22(b)), a large number of dimple structures elongated along shear direction show parabola shapes. Fig. 22(c) is a higher magnification micrograph of $E$ region. This region is not smooth and is covered by a large number of knobble structures between which there are many fine hollownesses and small flat surfaces which similar to melted surfaces. These results are similar to those obtained adiabatic shear fracture surfaces from hardened steel under high strain rate loading condition recently by Meyers et al. ${ }^{[67]}$ and Xu et al. ${ }^{[23]}$.

The observations in Fig. 22 show that the fracture surface is not flat and smooth, and most areas show the elongated dimple structures along the shear direction, therefore, these fracture surfaces have obvious characteristics of ductile shear fracture. A large number of experiments show that under high speed shear deformation, the severe elongated dimple structure on fracture surface is the most significant feature of adiabatic shear fracture ${ }^{[68,69]}$. These dimple structures were formed under the effect of shear stress when the adiabatic shear bands had been just pro- duced. Rogers ${ }^{[70]}$ explained the reason for this kind of the knobble structure formation. He believed that nucleation, growth and coalescence of microvoids led to adiabatic shear fracture, at the moment of fracture occurrence, the severely relative friction between the fracture surfaces causes the large heat, then the ligaments between the elongated dimple structures disappeared and the flat knobble structures are formed.

The observations indicate that adiabatic shear fracture is the primary reason of serrated chip formation during high speed machining of hardened steel. The adiabatic shear fracture is an accumulative process of microdamages. If shear band is in a thermal softening state when adiabatic shear initiates, fracture may occur in a ductile way controlled by nucleation, growth and coalescence of microvoids. The whole fracture process can be illustrated by a microcosmic fracture model in Fig. 23. In hardened steel, dispersed and fine particles of alloy carbide often become nucleation points of microvoids. At the initial stage of adiabatic shear, the deformation incompatibility between the hard carbide particles and the metallic matrix can cause cracking, and then a large number of very small cores of microvoid appear within shear band (Fig. 23(a)). At this stage, the material in the shear band is in a combined state of compression and shear stress, and the temperature is not high, therefore, the microvoids cannot growth rapidly. As the temperature in shear band increases, the microvoids begin to grow, coalesce and are elongated along shear direction under shear stress (Fig. 23(b)). Some macroscopic cracks appear after the microvoids are interconnected, then the adiabatic shear fracture occurs along shear band and finally the elongated dimple structures remain on fracture surface like that shown in Fig. 22(b) (Fig. 23(c) and (Fig. $23(\mathrm{~d}))$. A series of microcosmic fracture processes are accomplished instantaneously, so real time observation during experiment is very difficult. Therefore, this microcosmic fracture model presented in Fig. 23 will need more experiments to confirm.
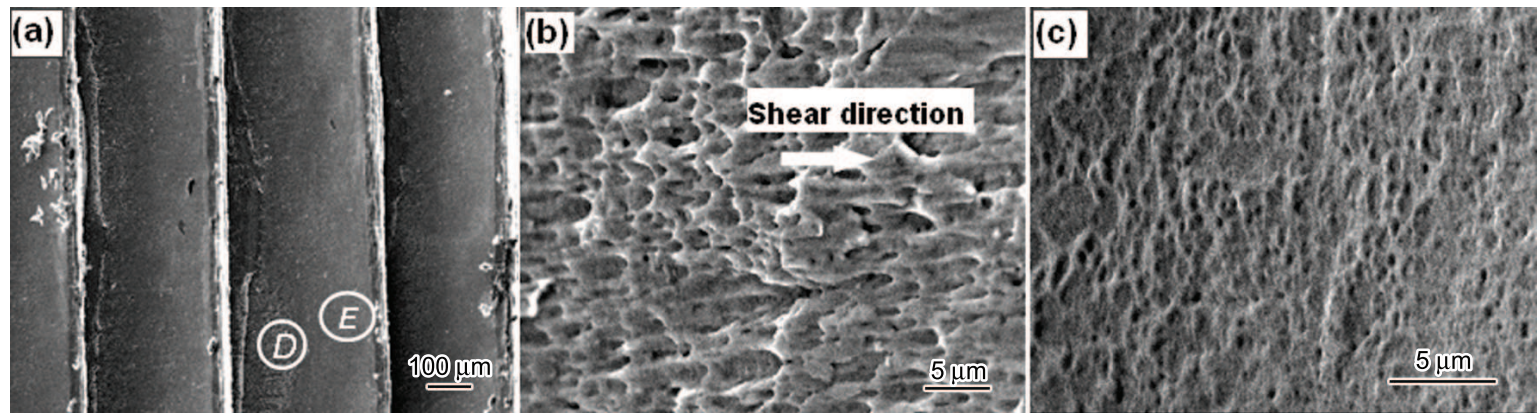

Fig. 22 Micrographs (SEM) of fracture surfaces of the serrated chip: (a) micrograph showing whole fracture surfaces; (b) higher magnification micrograph of D region in a showing; (c) higher magnification micrograph of $\mathrm{E}$ region in a showing Knobble structures due to heavy rubbing between fracture surfaces $\left(30 \mathrm{CrNi} 3 \mathrm{MoV} \text { steel, } V=300 \mathrm{~m} / \mathrm{min}, a_{\mathrm{p}}=0.215 \mathrm{~mm}, \gamma_{0}=-10^{\circ}\right)^{[55]}$ 


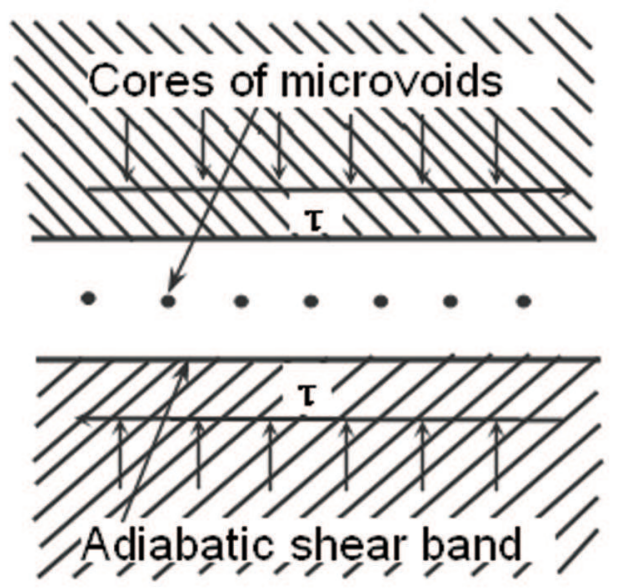

(a)
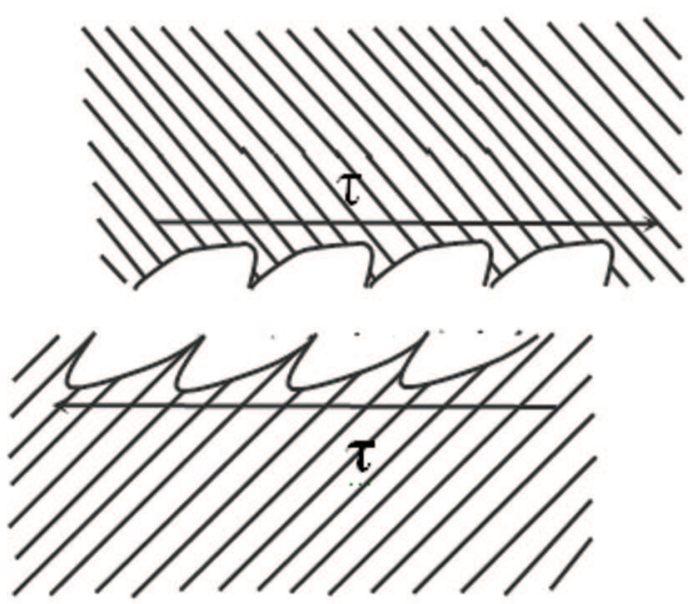

(c)

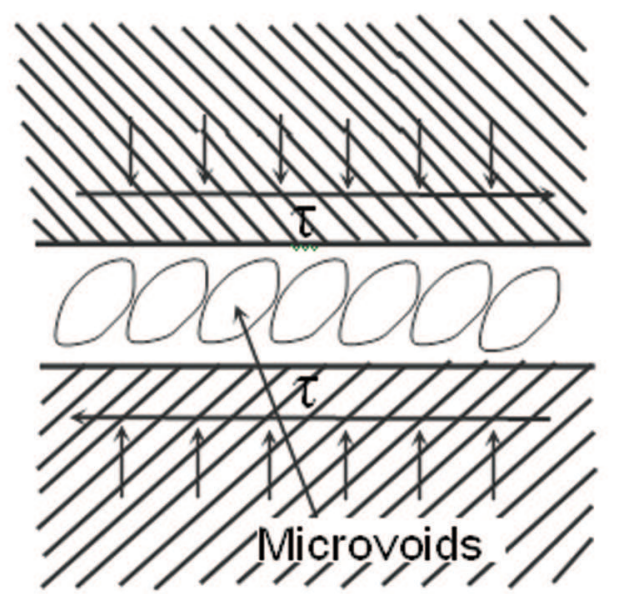

(b)

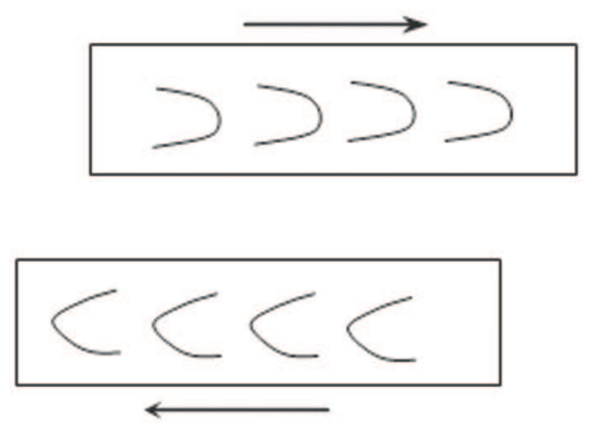

(d)

Fig. 23 Microcosmic model of adiabatic shear ductile fracture process occurring in adiabatic shear band through nucleation, growth and coalescence of microvoids: (a) nucleation of microvoids in adiabatic shear band; (b) growth and coalescence of microvoids along shear direction; (c) fracture of coalesced voids under shear stress; (d) elongated dimple structures along shear direction on adiabatic shear fracture surfaces ${ }^{[56]}$

\section{Conclusions}

(1) SEM observations show that the microstructures between the center of the ASBs and matrix are different. In the center regions of the ASBs, the grains are very small. The grains are elongated along the direction of chip flow in the transitional regions.

(2) The microhardness values in and near the shear bands decrease with the distance from the ASBs center until the matrix hardness reached, and the hardness in the center of the shear bands is higher than that of the common martensite.

(3) The HSM can produce two types of ASBs, the deformed shear bands and transformed shear bands. A lower cutting speed, it forms the deformed shear bands, and a higher cutting speed it results in the transformed shear bands. The formation mechanisms of the two types of ASBs are fundamentally different.

(4) The microstructure inside the ASBs varies from the band center to the normal chip material.
The transitional zone has severely elongated martensite laths with a low density of dislocations along the shear direction and the broken laths are divided by the areas of high dislocation densities. The central zone consists of many subgrains with a high density of dislocations and fine equiaxed grains. The dynamic recrystallization and phase transformation may occur simultaneously during the formation of the transformed ASBs.

(5) The microstructural evolution of dynamic recovery and recrystallization is the dominant metallurgical process during microstructural formation of ASBs. The dynamic rotational recrystallization is the origin of the equiaxed grains in the center of the ASBs.

(6) A microstructural evolution model of material in ASB during HSM of the hardend steel is proposed, including reorientation and elongation of the martensite laths along shear direction, partitioning of elongated subgrains, formation of subgrains with a high density of dislocations, formation of the equiaxed 
grain structure, and formation of the substructure in equiaxed grains.

(7) The fracture surface is characterised by the dimple structures, which are elongated along shear direction, and the knobble structures. The adiabatic shear fracture is the primary reason of the serrated chip formation during HSM of hardened steel.

(8) A microcosmic adiabatic shear fracture model during HSM of the hardened steel including nucleation, growth and coalescence of microvoids within ASB is built up.

\section{Further Investigations Proposed}

It is very hard to prepare the thin-foil for TEM examination due to the small space size of the shear bands. For a better understanding of shear localization, the measurement and systematic studies of microstructural evolution of the bands need to be pursued further. The focused ion beam (FIB) technique is recommended for the specimen preparation.

It is known that TEM has been one of the primary tools for characterizing the nano-, micro- and mesostructures of materials because of its high-resolution capabilities. For example, the TREM is now capable of producing interpretable information approaching $0.1 \mathrm{~nm}$ provided the sample examined is sufficiently thin. However, TEM still appears to have limitations for getting information of the microstructures of the bands. On the other hand, the choice of the field observed on the specimen is significantly restricted. Recently, SEM with Electron-Backscatter Diffraction (EBSD), particularly the use of EBSD in conjunction with a field-emission SEM (FEGSEM) has been used to characterize the microstructural evolution of the shear localization. The advantages of EBSD related to optical microscopy as the quantitative metallographic method are higher spatial resolution, more accurate data and more complete structure characterization. In particular, it can examine microstructural analysis on the bulk materials rather than thin foils ${ }^{[73-76]}$.

The transition of crystal lattice to nano-crystals and amorphous phase in the shear bands was found preliminary by Meyers ${ }^{[43]}$ and then by other author ${ }^{[77]}$, but this important finding need to be confirmed.

An in-depth understanding of the conditions required for production of the shear localization is needed for improved constitutive description of the thermoplastic instability. $\mathrm{Xu}$ and Meyers et al. ${ }^{[23]}$ proposed that there a combination of both the critical strain and strain-rate based on their experimental dada in Al-Li alloy, but this proposal need to do more work and further confirmation.

Even though the complex network of the bands has not been observed at present study, but this kind of multi-bands have occurred under other dynamic conditions in many cases, and Li et al ${ }^{[40,78]}$. used to offer a possible interpretation for the production, but more work still needs to do further.

In short, extreme deformation behavior of the materials is quite complex and also are impossible to monitor and require innovative approaches to interpret the behavior of matter in a period of several millionths of a second. Mechanics and materials researchers should come together to promote the understanding of the phenomena

\section{Acknowledgements}

This study was financially supported by the National Natural Science Foundation of China (Nos. 50875033, 50775018 and 51175063)

\section{REFERENCES}

[1] L. Zhen, D.L. Zou, C.Y. Xu and W.Z. Shao, Mater. Sci. Eng. A 527 (2010) 5728.

[2] F. Martinez, L.E. Murr, A. Ramirez, M.I. Lopez and S.M. Gaytan, Mater. Sci. Eng. A 454-455 (2007) 581.

[3] C.G. Lee, W.J. Park, S. Lee and K.S. Shin, Metall. Mater. Trans. A 29 (1998) 477.

[4] J. Krejei, J. Brezina and J. Buchar, Scr. Mater. 27 (1992) 611.

[5] J.S. Zhou, L. Zhen, Y.X. Cui and D.Z. Yang, J. Mater. Sci. Lett. 17 (1998) 391.

[6] D.H. Li, Y. Yang, T. Xua, H.G. Zheng, Q.S. Zhu and Q.M. Zhang, Mater. Sci. Eng. A 527 (2010) 3529.

[7] H.J. Yang and Y.B. Xu, J. Mater. Res. 24 (2009) 2617.

[8] Y. Yang and B.F. Wang, J. Mater. Sci. 41 (2006) 7387.

[9] Y. Yang and B.F. Wang, Mater. Lett. 60 (2006) 2198.

[10] Y. Yang, X.M. Zheng, Z.H. Li and Q.Y. Li, Acta Mater. 44 (1996) 561.

[11] P. Landau, A. Venkert and D. Rittel, Metall. Mater. Trans. A 41 (2010) 389.

[12] D. Rittel, P. Landau and A. Venkert, Phys. Rev. Lett. 101 (2008) 165501

[13] Q. Xue and G.T. Gray III, Metall. Mater. Trans. A 37 (2006) 2447.

[14] Q. Xue and G.T. Gray III, Metall. Mater. Trans. A 37 (2006) 2435.

[15] B. H.Wang, S. Lee, Y.C. Kimc, N.J. Kimb and D.H. Shin, Mater. Sci. Eng. A 441 (2006) 308.

[16] M.T. Perez-prado, J.A. Hines and K.S. Vecchio, Acta Mater. 49 (2001) 2905.

[17] J.A. Hines, K.S. Vecchio and S. Ahzi, Metall. Mater. Trans. A 29 (1998) 191.

[18] Y.B. Xu, H.J. Yang and M.A. Meyers, Scr. Mater. 58 (2008) 691.

[19] H. Yan, S.W. Xu, R.S. Chen, S. Kamado, T. Honma and E.H. Han, Scr. Mater. 64 (2011) 141.

[20] M.D. Nave, M.R. Barnett and H. Beladi, ISIJ Int. 44 (2004) 1072.

[21] M.Z. Quadir, M. Ferry, O. Al-Buhamad and P.R. Munroe, Acta Mater. 57 (2009) 29.

[22] Y.B. Xu, Y.L. Bai and M.A. Meyers, J. Mater. Sci. Technol. 22 (2006) 737. 
[23] Y.B. Xu, W.L. Zhong, Y.J. Chen, L.T. Shen, Q. Liu, Y.L. Bai and M.A. Meyers, Mater. Sci. Eng. A 299 (2001) 287.

[24] Y.B. Xu, J.H. Zhang, Y.L. Bai and M.A. Meyers, Metall. Mater. Trans A 39 (2008) 811.

[25] R. Komanduri and R.H. Brown, J. Eng. Ind. 103 (1981)33.

[26] R. Komanduri, T. Schroeder and J. Hazra, J. Eng. Ind. 104 (1982) 121.

[27] R. Komanduri, Wear 76 (1982)15.

[28] R. Komanduri and T. Schroeder, ASME PED 12 (1984) 287.

[29] J.Q. Xie, A.E. Bayoumi and H.M. Zbib, Int. J. Mach. Tools Manuf. 7 (1996) 835.

[30] J. Sheikh-Ahmad and J.A. Bailey, J. Manuf. Sci. Eng. 119 (1997) 307.

[31] G. Sutter and A. Molinari, J. Manuf. Sci. Eng. 127 (2005) 245.

[32] G. Sutter and N. Ranc, Int. J. Mach. Tools Manuf. 47 (2007) 1507.

[33] Z. N. Farhat, Mater. Sci. Eng. A 361 (2003) 100.

[34] T. I. EI-Wardany, H. A. Kishawy and M. A. Elbestawi, J. Manuf. Sci. Eng. 122 (2000) 620.

[35] Z.B. Hou and R. Komanduri, Metall. Mater. Trans. A 33 (2002) 2995.

[36] J.Q. Xie, A.E. Bayoumi and H.M. Zbib, J. Mater. Eng. Perform. 4(1) (1995) 32

[37] A.E. Bayoumi and J.Q. Xie, Mater. Sci. Eng. A 190 (1995) 173

[38] A. Molinari, C. Musquar and G. Sutter, Int. J. Plasticity 18 (2002) 443.

[39] T.J. Burns and M.A. Davies, Int. J. Plasticity 18 (2002) 487

[40] Q. Li, C.X. Ma and Z.H. Lai, J. Northeastern Uni. 16(1) (1995) 40 (in Chinese).

[41] Q. Li, C.X. Ma, Z.H. Lai, L.X. Yin, H. Liu and Y.J. Wang, Chin. J. Mater. Res. 11 (1997) 42 (in Chinese).

[42] S.H. Lu, N. He and Q.Y. Xie, Mater. Mech. Eng. 33(3) (2009) 61 (in Chinese)

[43] S.H. Lu and N. He, Mech. Sci. Technol. 28 (2009) 241 (in Chinese).

[44] H. Dong, D. Qu, H.T. Zhang and M. Li, J. Dalian Uni. Technol. 50 (2010) 921 (in Chinese).

[45] S.P. Wang, Chin. Mech. Eng. 23 (2012) 1117 (in Chinese).

[46] J.D. Puerta Velasquez, B. Bolle, P. Chevrier, G. Geandier and A. Tidu, Mater. Sci. Eng. A 452-453 (2007) 469.

[47] Z.P. Wan, Y.E. Zhu, H.W. Liu and Y. Tang, Mater. Sci. Eng. A 531 (2012) 155.

[48] C.Z. Duan and L.C. Zhang, Mater. Sci. Eng. A 532 (2012) 111

[49] C.Z. Duan and M.J. Wang, J. Mater. Sci. Technol. 20 (2004) 775

[50] C.Z. Duan and M.J. Wang, J. Mater. Process. Technol. 168 (2005) 102.
[51] C.Z. Duan, M.J. Wang and T. Dou, Adv. Mater. Res. 97-101 (2010) 1887.

[52] C.Z. Duan, Z.X. Wang, M.J. Wang and W.S. Kong, Appl. Mech. Mater. 52-54 (2011) 148.

[53] C.Z. Duan and M.J. Wang, Scr. Mater. 52 (2005) 1001.

[54] C.Z. Duan, Y.J. Cai, M.J. Wang and G.H. Li, J. Mater. Sci. 44 (2009) 897.

[55] C.Z. Duan, M.J. Wang, Y.J. Cai and T. Dou, J. Mater. Sci. Technol. 27 (2011) 625.

[56] C.Z. Duan, H.Y. Yu, H.H. Li and M.J. Wang, Adv. Sci. Lett. 4 (2011) 2493.

[57] C.Z. Duan and M.J. Wang, Mater. Sci. Technol. 12 (2004) 602 (in Chinese)

[58] C.Z. Duan and M.J. Wang, J. Dalian Uni. Technol. 44 (2004) 244 (in Chinese)

[59] C.Z. Duan and M.J. Wang, Mater. Mech. Eng. 28(10) (2004) 16 (in Chinese ).

[60] C.Z. Duan, M.J. Wang, J.Z. Pang and G.H. Li, J. Dalian Uni. Technol. 46 (2006) 355 (in Chinese).

[61] C.Z. Duan, M.J. Wang, G.H. Li and Y.J. Cai, Expl. Shock. Wav. 27(1) (2007) 91 (in Chinese ).

[62] C.Z. Duan, M.J. Wang, G.H. Li and T. Dou, J. Dalian Uni. Technol. 54 (2010) 502 (in Chinese ).

[63] C.L. Wittman and M.A. Meyers, Metall. Trans. A 21 (1990) 707.

[64] M.A. Meyers and H.R. Pak, Acta Metall. 34 (1986) 2493.

[65] Y.L. Bai, Res. Mech. 31 (1990) 133.

[66] B. Derby, Acta Metall. Mater. 39 (1991) 955.

[67] M.A. Meyers, Y.B. Xu, Q. Xue, M.T. Perez-Prado and T.R. McNelley, Acta Mater. 51 (2003) 1307.

[68] K.M. Cho, Y.C. Chi and J. Duffy, Metall. Trans. A 21 (1990) 1161.

[69] J.G. Cowie, M. Azrin and G.B. Olson, Metall. Trans. A 20 (1989) 143.

[70] H.C. Rogers, Annu. Rev. Mater. Sci. 9 (1979) 283.

[71] Y.B. Xu and M.A. Meyers, Mater. Sci. (2013) (accepted).

[72] Y.B. Xu and M.A. Meyers, in: D. Bradley and Y.L. Bai (eds.), Adiabatic Shear Localization (2nd Ed.), Elsevier, Amsterdan, 2012, pp. 111-171.

[73] F. Martine and L.E. Murr, Mater. Sci. Eng. A 454455 (2007) 581.

[74] J.F C. Lins and H.R.Z. Sandim, Mater.Sci. Eng. A 457 (2007) 205.

[75] H.J. Yang and M.A. Meyers, J. Mater. Res. 24 (2009) 2617.

[76] Y.B. Xu and M.A. Meyers. Chin. J. Mater. Res. 23 (2009) 562 (in Chinese).

[77] N. Li, Y.D. Wang, R.L. Peng, X. Sun, P.K. Liaw, G.L.Wu, L .Wang and H.N. Cai, Acta Mater. 59 (2011) 6369.

[78] Q.Li and M.N. Bassin., Mater. Sci. Eng. A 358 (2003) 128 